\title{
Exposure Treatment Vehicle Amount Unit
}

National Cancer Institute

\section{Source}

National Cancer Institute. Exposure Treatment Vehicle Amount Unit. NCI Thesaurus. Code C87884.

The unit of measure for the quantity of exposure to an excipient in a treatment. 